\title{
Gender Socialization in Chinese Kindergartens: Teachers' Contributions
}

\author{
Eve Siu Ling Chen • Nirmala Rao
}

Published online: 31 August 2010

(C) The Author(s) 2010. This article is published with open access at Springerlink.com

\begin{abstract}
Teacher-child interactions and peer exchanges were observed once a week for 10 months in four kindergartens in Hong Kong, China. A total of 206 anecdotes/ scenes considered representative of the gender-related experiences of 109 4-year-old Chinese children in these kindergartens were analyzed. Descriptive codes, generated iteratively were clustered, categorized, integrated, recoded and recategorized and led to the identification of two major themes related to the socialization practices of teachers: Gendered Kindergarten Routines and Perpetuation of Gender Stereotypes. Findings indicated that these early years' educational contexts were not gender neutral. Teachers interacted with boys significantly more than girls. They also subtly conveyed traditional Chinese gender values through their repeated use of gendered routines in the kindergartens and their behaviors reflected gender stereotypes.
\end{abstract}

Keywords Gender socialization · Kindergarten teachers . Gendered routines $\cdot$ Gender stereotypes

\section{Introduction}

Research on young children's gender socialization experiences in school settings in the United States and Australia (e.g., Alloway 1995; Blaise 2005; Thorne 1993) has documented the different experiences of boys and girls. However, there is a dearth of studies on preschoolers'

E. S. L. Chen $(\bowtie) \cdot$ N. Rao

Faculty of Education, The University of Hong Kong,

Hong Kong, China

e-mail: evechen@graduate.hku.hk

N. Rao

e-mail: nrao@hkucc.hku.hk gender socialization experiences (Maccoby 1998). Further, research on the gender socialization experiences of nonwestern children is underrepresented in the extant literature. Against this background, this study considered the gender socialization goals and strategies of Chinese kindergarten teachers in Hong Kong (Special Administrative Region, China). We were interested in examining whether or not they treated boys and girls with the same respect and supported every child to express ideas and participate fully.

Bronfenbrenner's (1989) ecological systems perspective which emphasizes the study of development within the context of four nested environmental contexts and conceives of socialization as an interwoven and reciprocal process guided our study design. We assumed that teacher-child interactions and supervised peer interactions in kindergartens are important in the gender socialization process and that teachers have a significant role in providing gender-fair early educational environments. We deployed naturalistic observation as the major method for collecting data as we felt that it would permit an open-ended, exploratory and interpretive approach to the investigation of young Chinese children's gender-related experiences.

Gender Socialization in Preprimary and Primary Settings

Gender is a cultural phenomenon (Williams and Best 1982) and socialization is a cultural practice of adults (LeVine 1998). Research conducted in western countries has documented parents' shaping of gender in the earliest years (e.g., Eckert and McConnell-Ginet 2003; Laflamme et al. 2002) and parents dress and name boys and girls differently soon after birth (Eckert and McConnell-Ginet 2003; Maccoby 2000). As children mature, they are increasingly connected with a wider social world and are socialized by adults outside the family (LeVine 1998). 
Previous studies conducted in school settings in western societies have suggested that teachers and peers have significant roles in children's gender socialization experiences (Duffy et al. 2001; Fromberg 2005; Koch 2003; Morgan 2001). Interestingly, Fagot et al. (1985) found that teachers' differential attention and responses toward common behaviors in American toddlers preceded the emergence of any gender differences in toddlers' behaviors that were measured. In the U.S., teachers' sponsorship of gender socialization of young children such as the practice of differential treatment has been investigated carefully and seriously (e.g., Sadker and Sadker 1994; Walkerdine 1998). For example, Thorne (1993) observed a preschool class in the U.S and noted that the adults who escorted their children into the preschool classrooms were predominantly female and the teachers perpetuated gender stereotypes by naming and dressing boys and girls as two distinctive groups starting from the very first day of preschool. She found that teachers segregated children by gender during classes and that children kept their distance from members of the other gender during recesses and lunch breaks. In the class, teachers divided the children by gender and let them compete with each others in gender groups. The antagonism that was created between boys and girls was used to motivate the children's participations in classroom learning. In the playground, the "cootie phenomenon" was repeatedly observed. Thorne observed that the American children regarded the touch from the peers of opposite gender as polluting. They screamed and rushed away to escape from cross-gender encounters during play time.

It should be noted that teachers are not necessarily aware of their stereotyped judgment and behavior. For example, subtle forms of gender inequity have been found in the teaching materials in preschools in the U.S with males more frequently and positively depicted and shown in a wider range of social roles compared to females (Diekman and Murnen 2004; Hamilton et al. 2006; Oskamp and Kaufman 1996; Sheldon 2004). Further, traditional gender values such as the importance of apparent beauty in girls and the significance of prominent strength and aggressiveness in boys had been repeatedly communicated to the children (Chick et al. 2002; Martin 1998). Australian kindergarten teachers have tended to regard girls as vulnerable victims who require adult help. Blaise and Andrew (2005) found that they readily interfered and blamed the boys when conflicts occurred between boys and girls. The observed pattern of teacher behaviors was taken for granted by the teacher and remained unquestioned until it was queried by the researcher.

In Asia, Hsieh (1995) and She (2000) have considered Taiwanese-Chinese teachers' contributions to gender socialization. Other than their work, few published studies have considered Chinese teachers' contributions to gender socialization and development in Hong Kong or other Chinese societies. There are no published empirical studies of gender socialization during the early school years in Chinese societies and the present study focused on Hong KongChinese teachers' gender socialization practices. Given Hong Kong's history as a former British colony for 155 years, it was assumed that there would be some commonalities in the gender-related experiences of Hong Kong-Chinese children and those residing in western societies. However the extent of these similarities is unknown. Hence one objective of this study was to empirically investigate the nature and forms of gender socialization techniques used by Chinese teachers. This would enable us to determine similarities and distinctions in the behaviors of Chinese teachers and those of their western counterparts, as reported in the existing literature.

\section{Gender Inequity and Stereotypes in Chinese Societies}

Guidelines on how to bring up boys and girls have been provided to Chinese parents through the ages and this advice is reflected in Chinese classical literature. For example, LiJi [The Book of Rites, 475-221 B.C.] recommends that from the age of ten girls ought to be confined at home and taught to be skillful homemakers and behave in humble and submissive ways. On the other hand, it was recommended that boys be sent to boarding school when they turned ten (Sturgeon 2008). In addition, gender roles and gender-appropriateness were clearly specified in "JiaoTe Sheng" (i.e., The Social Hierarchy and Obligations in the Society) which stated that women should follow and obey men throughout their life while men should play the role of the breadwinners and leaders of women (Sturgeon (Trans.) 2008). It was also recommended that men should seek to actualize themselves, rule their families, and govern their country (Theobald 2000). An old Chinese adage also affirmed the traditional belief of women's virtue lies in their having of no talent (Chen 1997).

The following song reflects traditional Chinese thinking about boys and girls and its content suggests that male privilege has its roots in thousands of years ago in ancient China. It recommends differential treatment of Chinese boys and girls right from their birth:

When a son is born

Let him sleep on the bed

Clothe him with fine clothes

And give him jade to play ...

When a daughter is born

Let her sleep on the ground.

Wrap her in common wrappings

And give broken tiles to play...

China: Book of Songs (1,000-700 B.C.)

Findings from recent studies conducted in mainland China suggest that male-centered gender values which 
existed thousands of years ago are manifest in contemporary society. For example, in response to the one-child policy which was announced in 1979 in China, the birth of girls in the less developed rural areas was sometimes not registered by parents who wished to have a son. This particular group of rural girls lived their entire lives without a legal identity and was deprived of some basic civic rights, including the right to compulsory education and the right to socialized medicine (Cai and William 2003). On the other hand, it was found that singleton daughters who lived in the developed urban areas during the same time period had started to enjoy unprecedented parental support because of the absence of brothers for their parents to favor (Fong 2002).

Before the 1980s many Hong Kong-Chinese parents, like their counterparts in contemporary rural China, explicitly preferred to have sons over daughters (Family Planning Association of Hong Kong, 1984, 1989, 1997) and sons were always granted priority if financial resources were relatively scarce (Salaff 1995). However, for the past 30 years school aged children in Hong Kong have not experienced much gender discrimination in the family. This was not the case in the education system wherein until 2001 girls were disadvantaged in the secondary school education system. In Hong Kong, students are segregated by achievement level (tracked) from Year 7 onwards. Previously, students were tracked into five ability bands but now there are three "Bands" of local schools, with Band 1 students being the highest achievers. The Secondary School Places Allocation Mechanism which has been in use since 1978 is used to track students into different schools. Until a court ruling in 2001, grades for boys and girls were calculated separately to determine their eligibility for secondary schools.

The High Court of the Hong Kong SAR announced in 2001 that the Hong Kong Government's practice of gender scaling and separate queues for fixed gender quotas in coeducational secondary schools was unlawful according to the Sex Discrimination Ordinance that was enacted in 1995. The Secondary School Places Allocation Mechanism was declared discriminatory, unfair, and biased against girls (Equal Opportunities Commission 2001). The judicial judgment was widely criticized as ignoring the gender difference in language development and being unfair to boys. The court case induced queries and complaints from the general public and eventually became a landmark case on gender inequity in Hong Kong education.

Nevertheless, it may not be appropriate to jump to a conclusion that male privilege was no longer manifest in the Hong Kong education system after 2001. Previous research has indicated that school experiences do not typically mitigate the adverse effects of traditional gender stereotypes but in some cases amplify them. For example, books such as "Failing at Fairness: How America's Schools Cheat Girls" (Sadker and Sadker 1994) have highlighted the negative effects of the differential treatment of boys and girls in the school settings in the U.S. There is a consensus that children's experience of differential treatment is pivotal for their early learning of gender differentiation (Ruble and Martin 1998). However, it has been argued that boys may not necessarily be advantaged by this differential treatment (Best 1983; Epstein et al. 1998; Hsieh 1995). In the present study, we considered whether male privilege was manifest in Chinese kindergartens and whether or not it benefitted boys.

In summary, there are few empirical studies on gender socialization of preschool age Chinese children and this study considered the following questions:

1. How do Chinese kindergarten teachers contribute to gender socialization of their students and are their behaviors similar to those of their western counterparts as reported in the extant literature?

2. Is male privilege manifest in Chinese kindergartens in Hong Kong and does it appear to benefit boys?

\section{Method}

\section{Participants}

Letters of invitation to participate in this study were sent to principals of 30 local kindergartens in Hong Kong. If the principal expressed initial interest, the first author arranged a face-to-face meeting to provide more information about the research. Convenience sampling was employed and four Chinese kindergartens were selected because the principals and teachers were committed to participating in the study. All four were private non-profit kindergartens serving the relatively mono-ethnic and predominantly Chinese communities in Hong Kong. A class of 4-year-olds was selected by principals in each of the four kindergartens.

All four kindergartens were located in comparable areas and served families from both working and middle class backgrounds. The educational level of the parents of the children ranged from primary to post-graduate education and their occupational status ranged from blue-collar to professional levels. Informed consent for participation was obtained from the parents of children enrolled in these classes and all other participants and the parents of 109 children (58 boys and 51 girls) gave explicit consent for their children to be videotaped.

Four Chinese female teachers (one from each kindergarten), ranging in age from 21 to 38 years of age, were observed and interviewed. All four teachers had completed secondary education and attained the minimum professional 
training qualifications required for kindergarten teachers (i.e., 360 hours pre-service or in-service teacher training) and were certified as Qualified Kindergarten Teachers in Hong Kong. Their assistant teachers and aides were observed when necessary.

\section{Procedure}

Weekly observations to the kindergartens were negotiated. Each visit to the fixed class of 4 -year-olds in each kindergarten lasted 3 to $3.5 \mathrm{hr}$, starting at 9 a.m.

The initial plan was to visit each of the four kindergartens once a week for 8 months resulting in 128 visits. However, only 105 visits were conducted over a period of 10 months. This is because (i) it was possible to visit only three kindergartens on some weeks on account of public holidays or special activities; (ii) visits could not be conducted when kindergartens were closed (Christmas and Chinese New Year holidays); (iii) all kindergartens in Hong Kong were shut for more than 7 weeks from the third week of March to the second week of May to halt the spread of SARS; and (iv) observations were conducted in July and August as kindergartens remained open over part of the summer to compensate for the days lost because of the earlier school closure.

During these 105 visits, information about teacher-child interactions across a variety of contexts and activities was obtained. Observations were conducted during morning assembly, whole-class teaching, small-group classroom activities, story time, snack time, toilet time, free play, birthday parties, performance rehearsals, and field trips. Behaviors in and out of the classroom in the four kindergartens and natural and emergent events were recorded by the first author. Observations were conducted as unobtrusively as possible and social interactions among the 109 children and their teachers were documented in field notes, photos and video clips.

For the first 5 months of data collection, hand-written field notes were made as the principals did not initially give consent for videotaping. After 3 months of being in the kindergartens, the principals granted permission to videotape as the first author had gained their trust. Over the 10-month data collection process, 235 hours of naturalistic observation were conducted in the four kindergartens. About 57.4\% (135 hr) of the observational data set was recorded by hand and the rest $(100 \mathrm{hr})$ was videotaped.

The frequencies of the teacher-boy and teacher-girl interactions were coded using a teacher-child interaction checklist during the first 5 months of the study. The checklist specified the emotional context of the interactions (i.e., positive, neutral, and negative), and 34 sub-categories of behavioral content (e.g., praising good behavior of a child, ordering the child to perform an action or responding to child's requests). Totally, $360 \mathrm{~min}$ of teacher-child interactions were coded over 12 30-minute sessions and, boys' interactions and girls' with their teacher were counted simultaneously.

Event sampling was used to describe teacher-child and supervised peer-child interactions. Detailed observational data about the context, antecedent, participants' behaviors, and consequence of teacher-child interactions and supervised peer-child interactions was mainly collected by the first author. The field notes and videotaped data were transcribed into anecdotes by event. Based on these 105 visits, 206 anecdotes/scenes considered representative of the gender-related experiences of the 109 children in the four kindergarten classes were coded. Scenes that were similar to these 206 occurred repeatedly in the same or different kindergartens observed but only one anecdote was counted. For example, (gender segregated) lining up to go to the toilet occurred several times during the day in each kindergarten. However, similar behavior was only coded once in each of the four data subsets (collected in the four participating kindergartens) and just accounts for four of the 206 anecdotes (e.g., Scene 2 from Kindergarten A on page 19, Scene 16 from Kindergarten B on page 22).

Procedures suggested by Creswell (2005, pp .231-246) were applied to the raw data. Coding by hand was facilitated by tools such as colored pens, highlighters, punctuations (e.g., brackets, arrows, boxes) and transcripts of the observational data with wide side margins (p.240). The coding of 206 scenes was similarly started with a mechanical procedure of segmenting. The mechanical segmenting was followed by an interpretational procedure of code assignment. The interpretation of text segments was based on a single conceptual question, that is, "what is it about?" The physical setting, ecological context, perspective, process, strategy, activity, pattern, or underlying meaning of each text segment was identified and short descriptions were written in the left margin. Reflections or remarks were jotted down in the right margin. Then, concrete and distinctive code labels were assigned to represent corresponding ideas. "In vivo codes" (i.e., the actual words of the participants) were preferred when possible and were marked using highlighters. Previously generated code labels were applied to the latter part of coding and new descriptive code labels were assigned when the existing code labels did not apply. The coding scheme was reviewed and refined repeatedly by clustering similar codes, looking for overlaps, and eliminating redundancies. The developing themes and the resulting generated themes were signified by different colors. The codes were categorized and re-categorized until four themes emerged as a result of the categorization and clustering in the reiterative process of content analysis. Two of these themes were related to teachers' contribution to gender socialization 
and are the foci of this paper. They are "gendered kindergarten routines" and "perpetuation of gender stereotypes".

\section{Inter-Rater Reliability}

The first author, a Hong Kong-Chinese woman whose educational background includes degrees in anthropology, psychology and education, conducted all the observations in the four kindergartens. Some steps were taken to lower and assess gender-bias in the sampling of observations by involving two Chinese men. The first, a postgraduate student in Gender Studies, was paid to collect data in two kindergartens and discuss them with the first author. In order to also incorporate a male perspective in subsequent interpretations of the observational data, the other man who had a Bachelor degree in Psychology and a Master degree in Education was invited to code, interpret, and comment on a sample of anecdotes.

The postgraduate student in Gender Studies (referred to as the male coder hereafter) observed teacher-children interactions for $390 \mathrm{~min}$ in two of the four kindergartens. This was because only two of the kindergarten principals gave consent for him to visit their kindergartens for assessing inter-rater reliability. Independent descriptions of the taped observations in the two kindergartens were provided by the student and were compared to those from the first author for the purpose of reaching consensus on the accuracy of event descriptions after the visits.

Inter-rater reliability between the female and male coders was evaluated on the teacher-child interaction checklist described earlier. As there were 34 sub-categories of behavioral content of teacher-child interactions, there were hence 34 possible responses for each of the 13 30-min intervals for boys and the same number of possible responses for girls. The data from this checklist were further aggregated to form three categories of emotional context of teacher-child interaction (positive, neutral, negative) for boys and the same three categories for girls. Hence for each of the 13 30-min interval, six categories of behavior could have been selected. Hence there were a total of 78 intervals in which the two coders could agree/ disagree. Cohen's Kappa was .78 which indicated the interrater reliability in the study was acceptable.

The male coder also contributed to the evaluation of code assignment. Based on discussions between him and the first author, descriptive code labels were repeatedly sorted, related, combined, and renamed into broader themes. The other man evaluated 20 anecdotes. He was initially provided transcripts of 40 anecdotes chosen randomly and provided in no particular order from the 206 anecdotes. He was requested to independently analyze and interpret the observational data that were transcribed by the first author and to choose at least 20, and any 20 out of the 40 anecdotes provided. He assessed the first 20 anecdotes provided. An examination of the 20 anecdotes indicated that seven were from Kindergarten A, eight were from Kindergarten B, and five were from Kindergarten D. His interpretations and conclusions were compared with those of the first author.

\section{Results}

\section{Key Findings}

\section{Variations Across Kindergartens}

The physical and institutional structures of the four kindergartens varied. Kindergartens $\mathrm{A}$ and $\mathrm{B}$ were in older buildings than the other kindergartens and the boys' and girls' toilet were at opposite ends of the kindergartens whereas they were adjacent to each other in Kindergartens $\mathrm{C}$ and $\mathrm{D}$. The adult-child ratios also varied across kindergartens. For example, the teacher in Kindergarten A managed 29 children with the occasional help of a female assistant teacher, whereas the teacher in Kindergarten B typically managed 33 children and seldom received help from the other teachers or aides. The teacher in Kindergarten $\mathrm{C}$ managed 23 children with the regular help of one assistant teacher and the occasional help of an extra aide and the teacher in Kindergarten D managed 24 children with the regular help of one assistant teacher. The student-teacher ratios in participating kindergarten are presented in Table 1.

\section{Representativeness of Observations}

Among the 105 visits to kindergartens, 91 occurred on "typical" school days. About 1.5 hours in each of the 14 atypical school days were spent on regular school activities. Hence, most of the anecdotes were drawn from typical school days.

As mentioned earlier, the main teachers in the four kindergartens were Chinese females. In Hong Kong, as in other parts of the world, kindergarten teachers are predominantly female (less than $1 \%$ of teachers were male in 2007) and this has gendered the context of interactions in kindergartens.

\section{Quantitative Analyses}

Drawing upon the independent coding of the same taped observations in Kindergartens A and D by the two coders the number of times teachers used gender labels was enumerated. These means were adjusted for the number of boys, number of girls and total number of children in the 
Table 1 Teacher-student ratios

The number of teachers in Kindergarten A, B, C and D classrooms were calculated to be 1.5 , $1.2,2.5$, and 2.0 , respectively

\begin{tabular}{lllll}
\hline Kindergarten & Number of boys & Number of girls & Total & Teacher to Student Ratio \\
\hline A & 17 & 12 & 29 & $1: 19.3$ \\
B & 19 & 14 & 33 & $1: 27.5$ \\
C & 9 & 14 & 23 & $1: 9.2$ \\
D & 13 & 11 & 24 & $1: 12.0$ \\
\hline
\end{tabular}

class. Results indicated that teachers used the gender label "Boys" and "Girls" .69 and .55 times per head per hour, respectively. This represents a ratio of 1.25: 1 . Teachers used these labels for administrative convenience, to indicate their approval or disapproval, and to give instructions to different gender groups.

Four Gender $(2) \times$ School (4) ANOVAS were applied to data on the frequency of teacher-child interactions. Dependent variables were the overall interactions (i.e., the total number of teacher-child interactions) and the numbers of positive, neutral, negative interactions. Significant main effects of School, $F(3,23)=21.49(p<.001)$, Gender, $F(1$, $23)=97.91(p<.001)$, and the School $\times$ Gender, $F(3,23)=$ $18.89(p<.001)$, were obtained for Overall teacher-child interactions. The same pattern of results was obtained for Positive and Neutral teacher-child interactions. However, only the main effects of school and gender were significant for Negative teacher-child interactions. Further, none of the post-hoc pair-wise comparisons for School were significant for all four analyses.

As shown in Table 2, statistical analyses confirm that teachers interacted significantly more with boys than girls, regardless of emotional context of the interaction.

The number of teacher-child interactions across gender and emotional context (positive, neutral, and negative) were also calculated. Once again, means were adjusted according to the number of boys and girls in the class. Among teacher-boy interactions, $67.51 \%$ were positive, $17.42 \%$ were neutral, and $15.08 \%$ were negative. However, $73.42 \%, 14.17 \%$, and $12.41 \%$ of the teacher-girl interactions were positive, neutral, and negative, respectively. As shown in Table 3, there were 8.16 incidents of teacher-boy interactions per head per hour and 3.78 incidents of teachergirl interactions per head per hour across the four kindergartens. The ratio of teacher-boy interactions to teacher-girl interactions was 2.16:1.

\section{Types of Gender-Socialization}

Each of the 206 anecdotes described an event of teacherchild interaction or supervised peer-child interaction. Interestingly not even one of these 206 anecdotes involved the direct teaching of gender values and beliefs. Two overarching themes which described teachers' contributions to gender socialization were identified but they were not mutually exclusive. As shown in Table 4, 42 of the 206 anecdotes had documented "gendered kindergarten routines" and 78 showed teachers' contributions through "perpetuation of gender stereotypes". Among these, 28 were coded under both gendered kindergarten routines and the teachers' perpetuation of gender stereotypes. Sixty-eight of the 78 anecdotes which showed teachers' contributions through "perpetuation of gender stereotypes" were coded as perpetuation of gender traits, behaviors, and occupational roles. Ten anecdotes were coded as teachers' perpetuation of male privilege. Among these ten anecdotes, seven also exemplified the theme "gendered kindergarten routines". However, none of the anecdotes under the theme "perpetuation of gender stereotypes" were coded as perpetuation of female privilege.

\section{Theme 1: Gendered Kindergarten Routines}

\section{Teacher-Directed Context of Interactions}

On a typical day, children arrived at their kindergartens between 8:45 and 9:00 with the bus mother or adult female members of their family. When they entered the classroom, they greeted their class teachers and went to their assigned seats located around several big tables. Normally, the children simply sat down and waited for further instructions from the teacher. Lessons typically began with a whole-class thematic session and children had several teacher-led activities throughout the day. Children completed assigned work sheets, listened to stories, had music and P.E. lessons, engaged in creative activities and had snacks. When a child had finished the assigned class work and creative arts activities, he or she would be permitted to engage in free play until teachers announced the end of all activities, which was about $15 \mathrm{~min}$ before the end of the school day. The children who took the school buses left the classroom as directed by their teachers and boarded the school bus under the supervision of the teaching aide(s) in the school. The other children stayed behind and waited in the classroom until their teacher dismissed them when the adults, predominantly female adults from their family came to collect them.

Observational data suggested that the Chinese children's days in the kindergartens were largely teacher-directed. The 4-year-old children were repeatedly required by their class teacher to act in a proper manner. Whenever children failed 


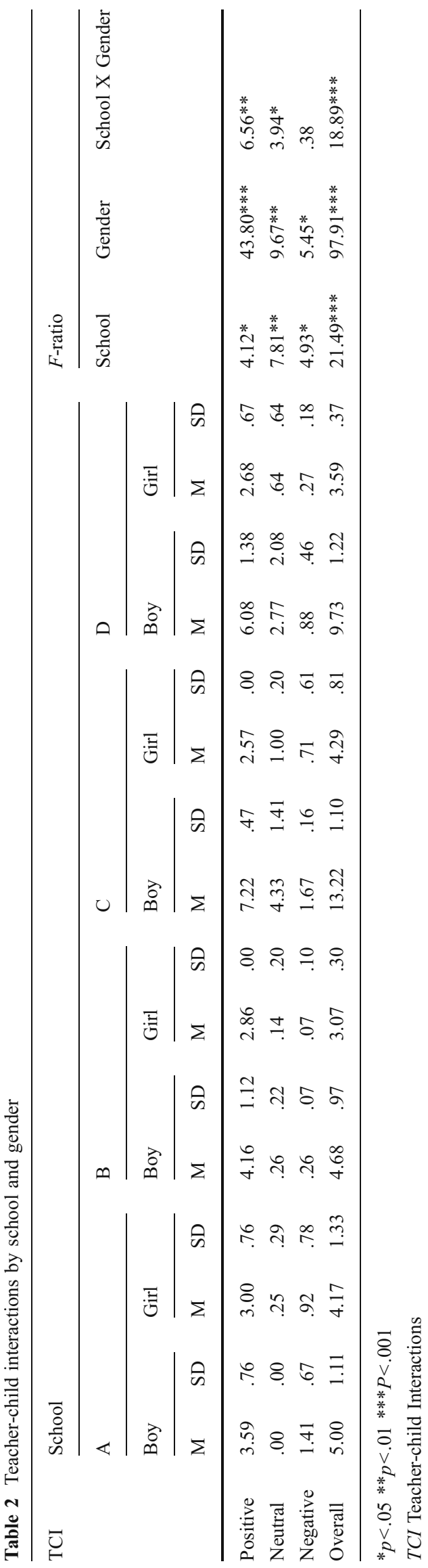

to do so, their teacher usually exercised power, halted the on-going activity and expressed her disapproval. In order to maintain or regain order in the classroom, teachers in the kindergartens punished or threatened to punish misbehaving children from time to time. The four kindergarten teachers exercised considerable power in the classroom and actively interfered to stop behaviors which they considered inappropriate.

The data suggest that the quantity of teacher-child interactions was high in each typical 3-hour long school day. However, when the emotional context of teacher-child interaction was taken into consideration, the quantitative findings further suggest that boys experienced more negative interactions per head per typical school day compared to their female classmates. Similarly, it was also observed that negative interactions frequently occurred between teachers and the children, particularly the boys though not only the boys, who showed relatively poorer self-control and appeared disobedient when compared to their female classmates. The following anecdote documents a negative interaction between a boy and his teacher:

Dong-Zai kept talking to the other children, making faces and noises while Miss $\mathrm{Hu}$ was talking. Miss $\mathrm{Hu}$ told Dong-Zai to stop but he ignored her. Miss Hu walked toward Dong-Zai, grasped his arms and stared into his eyes. Miss Hu repeated her order firmly, "I sa-i-d s-t-o-p it!" Dong-Zai appeared as though his arms were in pain. Finally, Miss Hu dragged DongZai to the front of the class and made him stand in front of the whole class while she taught. Dong-Zai sulked and kept on rubbing his arms. (Scene 206)

\section{Functional Use of Gender Labels}

Children's kindergarten experiences were highly structured by gendered daily routines. For example, two long parallel lines made on the classroom floor using blue- and red-colored electric wire tape were used for gender segregation. Usually, boys were required to line up along the blue line and girls were instructed to line up along the red line before the children were allowed to leave the classroom during transitions. There were approximately seven routine transitions in a typical school day. The boys and girls were thus segregated by gender at least seven times during the 3-hour school day. Sometimes, the kindergarten teachers used competition to motivate children to segregate themselves by gender quickly. For example:

... Miss Hu told the children to line up for toilet by saying, 'Let us see if the boys' team or the girls' team will be the first group to line up nicely?" The boys and girls lined up quickly and separately along the designated blue and red lines... (Scene 2) 
Table 3 Number of teacherchild interactions across emotional context and gender

\begin{tabular}{lllll}
\hline & Boys & Girls & Total & Boys to Girls Ratio \\
\hline Positive interactions & $5.25(67.51 \%)$ & $2.78(73.42 \%)$ & 8.04 & $1.89: 1$ \\
Neutral interactions & $1.85(17.42 \%)$ & $.51(14.17 \%)$ & 2.35 & $3.63: 1$ \\
Negative interactions & $1.06(15.08 \%)$ & $.49(12.41 \%)$ & 1.55 & $2.16: 1$ \\
Overall interactions & $8.16(100.00 \%)$ & $3.78(100.00 \%)$ & 11.94 & $2.16: 1$ \\
\hline
\end{tabular}

Gender labels were also used extensively by teachers during physical activities sessions, music and movement sessions, and computer sessions. The anecdotes shown below illustrate how gender labels were used to segregate children.

...During P.E. time in Kindergarten D, the boys and girls were asked to line up separately before they were led to the playground. In the playground, the boys and girls were separated into boys' and girls' groups. First, all boys were allowed to play on the slide under a female teaching assistant's supervision. At the same time, all girls were told to play the game "Mr. Noodle" on the other side of the playground under Miss Zhang's instructions. The boys played happily in one half of the playground while the girls played cheerfully at the other half of the playground. After about $10 \mathrm{~min}$ later, the boys and girls changed activities and this time the girls played on the slide and the boys played the game "Mr. Noodle" under Miss Zhang's supervision. Again, the girls and the boys played with their same-gender playmates pleasantly in two separated play-zones (Scene 40).
...During group-activity time in Kindergarten A, Miss $\mathrm{Hu}$ instructed her class to form smaller groups. Miss $\mathrm{Hu}$ explained how to form smaller groups from the larger groups of children sitting at the same table. Miss $\mathrm{Hu}$ illustrated, "For example, Nana, Sisi, and Yingying [all girls] form one group. The other children [all boys] form another group" (Scene 66).

It is noteworthy that the common practice of gender segregation was purposefully suspended for the boys' benefit during snack time in one of the four participating Chinese kindergartens.

...In the $\mathrm{K} 2$ classroom at Kindergarten $\mathrm{C}$, Wenwen made a suggestion to Miss Yuan when snack time began. Wenwen said, "Boys and girls should be separated in two lines to get their snacks." Miss Yuan replied, "Not necessarily. We have more boys than girls in our class. If you were separated into a boys' line and a girls' line, the boys would have to wait for a very long time to get their snacks" (Scene 53).

Table 4 Examples of the categories which emerged from the coding of the anecdotes $(N=206)$

\begin{tabular}{|c|c|c|c|c|c|c|c|c|c|c|c|c|c|c|c|}
\hline \multirow[t]{5}{*}{ Scene } & \multicolumn{15}{|c|}{ Gender Socialization } \\
\hline & \multirow{2}{*}{\multicolumn{3}{|c|}{ Participants }} & \multicolumn{4}{|c|}{ Context } & \multicolumn{8}{|c|}{ Content } \\
\hline & & & & \multicolumn{2}{|c|}{$\begin{array}{c}\text { Teacher } \\
\text { contribution }\end{array}$} & \multicolumn{2}{|c|}{$\begin{array}{c}\text { Peer } \\
\text { contribution/ } \\
\text { self regulation }\end{array}$} & \multicolumn{3}{|c|}{ Teacher contribution } & \multicolumn{2}{|c|}{ Peer contribution } & \multicolumn{3}{|c|}{$\begin{array}{c}\text { Self regulation/ } \\
\text { Internalization of norms }\end{array}$} \\
\hline & \multirow[t]{2}{*}{ TCI } & \multirow[t]{2}{*}{ SCI } & \multirow[t]{2}{*}{ TSCI } & \multirow[t]{2}{*}{ GKR } & \multirow[t]{2}{*}{ Other $^{1}$} & \multirow[t]{2}{*}{ GP } & \multirow[t]{2}{*}{ Other $^{1}$} & \multicolumn{2}{|c|}{ POGS } & \multirow[t]{2}{*}{ Other $^{2}$} & \multirow[t]{2}{*}{ POGS } & \multirow[t]{2}{*}{ Other $^{2}$} & \multirow[t]{2}{*}{ POGS } & \multirow[t]{2}{*}{$\mathrm{SC}$} & \multirow[t]{2}{*}{ Other $^{2}$} \\
\hline & & & & & & & & POGGS & POMP & & & & & & \\
\hline 1 & $\sqrt{ }$ & & & $\sqrt{ }$ & & & & $\sqrt{ }$ & & $\sqrt{ }$ & & & & & \\
\hline 2 & $\sqrt{ }$ & & & $\sqrt{ }$ & & & & $\sqrt{ }$ & & & & & & & \\
\hline$:$ & & & & & & & & & & & & & & & \\
\hline : & & & & & & & & & & & & & & & \\
\hline 206 & $\sqrt{ }$ & & & & & & & $\sqrt{ }$ & & $\sqrt{ }$ & & & & & \\
\hline Subtotal & 72 & 91 & 43 & 42 & & 72 & & 68 & 10 & & 51 & & 10 & 23 & \\
\hline
\end{tabular}

Categories are not mutually exclusive

TCI Teacher-child Interactions; SCI Supervised Child Interactions; TSCI Teacher-child Interactions and Supervised Child Interactions; GKR Gendered Kindergarten Routines, GP Gendered Play; POGS Perpetuation of Gender Stereotypes; POGGS Perpetuation of General Gender Stereotypes (e.g., "gender traits", "gender behaviors", and "gendered occupational roles" etc.); POMP Perpetuation of Male Privilege (e.g. "male-centeredness", "more time for boys", "more attention to boys", "more learning opportunities for boys", and "Boys First Rule" etc.); $S C$ Self-censuring; Others 1 Scenes that cannot be categorized under the 2 major context categories (i.e., "gendered kindergarten routines" and "gendered play"), for example, the scenes of context such as "class teaching" and "classwork" etc; Others ${ }^{2}$ Scenes that cannot be categorized under the 2 major content categories (i.e., "perpetuation of stereotypes" and "self-censuring"), for example, "home-school cooperation" and "cross-typed behaviors" etc. 
The frequency of teachers' functional use of gender labels during a typical day in the kindergarten was calculated. Results indicated that teachers of a class of 15 boys and 15 girls used gender labels about 56 times per typical day. They used them for administrative convenience, for motivation and as a means of reward and punishment. However, gender labels were not used in Kindergarten $\mathrm{C}$ when the teacher felt that it would disadvantage boys. This suggests that teachers may believe that they had taken the best interests of their students into consideration when making decisions of teaching practice. However, teachers may not aware of the importance of gender equity when there was conflict of interest.

\section{Theme 2: Perpetuation of Gender Stereotypes}

Teachers actively perpetuated gender stereotypes through perpetuating certain gender stereotypes and granting male privilege.

\section{Differential Attention}

As noted earlier, teachers interacted with boys more than girls. Consistent with the quantitative data collected, the qualitative data suggested that teachers usually overlooked the off-task behaviors of girls but attempted to engage boys who were off-task in classroom learning:

...The whole-class thematic teaching session was about to start. Miss Mao instructed all the children to gather and sit on the floor. Nana sat in the front row but she seemed to be uninterested in what was going on in the classroom. While most of the children in the class were listening attentively, Nana was daydreaming and was biting her finger nails. Dong-Zai sat at the second row and was quite near to Nana. Dong-Zai also seemed uninterested in the teachers' instruction and made faces and distracted the boys sitting around him. Miss Mao called Dong-Zai's by name several times, asked him to answer a few questions, and even invited him to come to the front of the class and demonstrate a procedure. Miss Mao kept on praising Dong-Zai's performance and acknowledged his answers. However, the teacher ignored the fact that Nana was daydreaming throughout the whole session. (Scene 201)

Although Table 3 indicates that boys garnered more teacher attention than girls, teachers' lower levels of tolerance for boys' off-task and inappropriate behaviors is noteworthy. It was repeatedly observed that boys were stopped from being off-task as soon as they started behaving that way and reminded to focus on the task at hand, especially in Kindergartens A and B. However, the girls' off-task behaviors were usually ignored and they remained free to day-dream or engage in inappropriate behaviors. The anecdote below illustrated different reactions to off-task behaviors which were exhibited simultaneously by a boy and by a girl:

... Sisi had a pink mini mirror and a pink lip balm in her pocket. Sisi kept putting on the lip balm and admiring herself in the mirror. Miss Mao noticed Sisi's off-task behavior but she continued to teach and didn't intervene. When Miss Mao was teaching, Miss $\mathrm{Hu}$ was responsible for managing the students in the classroom. Miss $\mathrm{Hu}$ also noticed Sisi's off-task behavior but she did not stop it. Meanwhile, Miss $\mathrm{Hu}$ also noticed that Jian-Zai was holding a pink fluorescent pen in his hand. Although Jian-Zai was just admiring his fluorescent pen quietly, Miss $\mathrm{Hu}$ threatened to confiscate Jian-Zai's fluorescent pen if he kept on playing with it. Moments later, Miss Hu grasped the fluorescent pen from Jian-Zai and put it back into Jian-Zai's schoolbag and zipped it up (Scene 60).

\section{Male Privilege}

Content analysis revealed that none of the 206 anecdotes documented the kindergarten teachers' perpetuation of female privilege. Even so, 10 (4.85\%) of the 206 anecdotes documented the kindergarten teachers' perpetuation of male privilege with seven $(70 \%)$ among the ten sampled events documented the teachers' perpetuation of male privilege through the administration of gendered kindergarten routines. Furthermore, it was observed that male privilege particularly prevailed and was taken for granted among the teachers and children in Kindergartens A and B. Coded observations such as the anecdote below demonstrated that male privilege had become an unquestioned part of the gendered daily routines in Chinese kindergartens in Hong Kong:

... Miss Cao led the boys to the bathroom to wash their hands and supervised them closely. The girls were left to walk in line to the girls' bathroom for hand-washing on their own. The girls lined up neatly and quietly in the hallway after they took turns to wash their hands in the girls' toilet. The girls waited for about $10 \mathrm{~min}$ before the boys returned with Miss Cao. The girls looked bored. Some girls started to lean against the wall of the hallway. A girl called Lanlan squatted on the floor. The girl Anan tried to comfort the sad-looking Lanlan by patting her gently on her head. The girl Shishi tut-tutted to show her 
impatience. When Miss Cao and the boys appeared at the other end of the hallway, Shishi muttered, "Boys go in first. Girls wait for a moment!" As usual, Miss Cao let the boys enter the classroom first. Then, Miss Cao told the girls to go back to their seats (Scene 16).

It was remarkable that the same privilege of teacher attention and care was not granted to the girls. It was equally noteworthy that the teachers issued rewards for desirable classroom behaviors to gender groups. Coded observations such as the one shown below illustrated that the privilege of being the first gender group of children to return to their seats was utilized as a reward to positively reinforce desirable behaviors among the 4-year-old girls. It was striking that the coded observations showed that the 4-year-old Chinese girls had to earn their privilege by behaving well. Nevertheless, their boy classmates were frequently given the privilege of first priority for no apparent reason. For example:

... The girls lined up and walked back to their classroom after taking turns to use the toilet. As usual, the girls waited in the hallway outside of their classroom for the teacher Miss Cao and the boys. When Miss Cao came back with the boys, she let the girls enter the classroom first. Usually, boys entered the classroom first. Miss Cao made her announcement and said, "Girls can go in first because the boys did not line up nicely" (Scene 28).

As noted in other anecdotes, boys tended to misbehave more than girls when lining up. The class teacher took girls' good conduct for granted and they were not granted the privilege of entering the classroom first. Therefore, the class teacher's double standard of good/desirable behavior in boys and girls was interpreted as not being fair to the girls and Scene 28 was thus categorized under the codes "unfairness to girls", "differential expectation", and "differential treatment". The teacher's routine and unquestioned practice was coded as "gendered kindergarten routines". The two codes "differential expectation" and "differential treatment" were further recoded as "male-centeredness" and categorized under the code "male privilege". The code "unfairness to girls" was categorized under the code "gender inequity". The two codes "male privilege" and "gender inequity" were re-coded as "male-biased Chinese culture" which was categorized under the code "gender stereotypes" and further categorized under the theme "perpetuation of gender stereotypes".

The teacher-child interactions described in the transcribed text of Scene 16 were also interpreted as reflecting Chinese gender values. In Scene 16, the 4-year-old girls witnessed their class teacher's cultural choice of choosing to look after the boys but not girls while going to wash their hands, something that occurred three to four times on a typical school day. The girls repeatedly observed the differential treatment several times each day and learnt to take the "Boys First Rule" for granted. The girls learnt about the "Boy First Rule" and the zero sum dynamics between boys and girls through observations in the institutional context of their kindergarten. Therefore, codes such as "Boys First Rule" and "zero-sum dynamics" were generated. The "Boys First Rule" was categorized under the code "male privilege" and "gender inequity". The "zerosum dynamics" was categorized under the code "gender antagonism". The code "gender antagonism" was further categorized under the code "gender stereotypes". The two codes "male privilege" and "gender inequity" were recoded as "male-biased Chinese culture" which was categorized under the code "gender stereotypes" and further categorized under the theme "perpetuation of gender stereotypes".

It is important to mention that the coding of such sampled events was sometimes controversial during the study. Although the man who evaluated 20 (about 10\%) of anecdotes agreed to most of the female coder's interpretations of the observational data, the male perspective he provided was inspiring when there were disagreements. The major difference between the interpretations made by the female coder and the male was about the beneficiaries of the differential treatment practiced by the kindergarten teachers. The man suggested "overprotection for boys" as the code for the sampled events such as Scene 16. When the first author suggested coding the behavior as "gender inequity" and "gender bias against girls", he disagreed and stood by his original code. He felt that the male privilege granted by the female kindergarten teachers such as the "Boys First" practice might not be fair and beneficial to the boys in a long run.

\section{Discussion}

The present study examined the nature of Chinese kindergarten teachers' gender socialization practices. Explicit, direct teaching of gender values and beliefs was not observed even once over the 10-month observation period in the four kindergartens in Hong Kong. The most recent Guide to Pre-primary Curriculum (Curriculum Development 2006) published by the Hong Kong SAR Government does not include gender education or the teaching of knowledge, skills, and attitudes about gender as a part of the formal curriculum of early childhood education in Hong Kong. Thus, teachers were not obligated to talk to children about gender or provide gender fair educational environments. These teachers' contributions to gender socialization were subtle and part of the hidden curriculum. 
Gender Segregation

\section{Use of Gender Labels}

In the U.S., kindergarten and elementary school teachers frequently applied gender labels such as "Boys" and "Girls" to categorize and segregate children for administrative and managerial convenience (Thorne 1993). Bigler (1995) conducted a 4-week experimental study with 6-year-olds in the U.S and results suggested a causal relationship between the functional use of gender categories and statistically significant increases in gender stereotyping, particularly among those children with less advanced classification skills. Based on Bem's (1981) gender schema theory, her findings suggest that teachers and adults should refrain from grouping young children on the basis of gender when children's classification skills are limited and gender stereotypes are forming. Consistent with the common practice of functional use of gender among teachers in the U.S., the Chinese kindergarten teachers in our study also frequently made use of gender labels. Indeed, they used them about 56 times within a 3 -hour session. It is likely that the Chinese teachers in the present study were not aware that their functional use of gender may promote the development of gender stereotypes.

\section{Gendered Kindergarten Routines}

Results also suggested that gendered kindergarten routines were common in the Chinese kindergartens as in school settings in the U.S. (Maccoby 1998; Thorne 1993). Further, a playful context of competition was often introduced to motivate the kindergarten children to segregate themselves by gender quickly.

The functional use of gender segregation could be argued as a necessity during toilet time because the children use different bathrooms based on their gender. Anecdotes such as Scene 40 and Scene 66 that were considered earlier have suggested that unnecessary gender segregation has been widely extended into many other teaching and learning activities such as the physical activities sessions, the music and movement sessions, and computer sessions. Observations illustrated that the 4-year-old boys and girls were usually assigned to receive similar teacher instructions and use the same equipment and teaching materials in gender-segregated groups. However, it is not apparent whether or not gendered kindergarten routines cater to the differing educational needs of boys and girls. Indeed these gendered kindergarten routines might not benefit either girls or boys.

Children were consistently and frequently reinforced to segregate themselves from the other gender by operant conditioning to comply with the traditional Chinese social norm of gender segregation (Sturgeon 2009). Nevertheless, observations such as Scene 53 indicated that the Chinese kindergarten teachers' usage of gendered kindergarten routines were conditional and tended to be male-centered.

The student teacher ratio in kindergartens in Hong Kong has decreased from 12.3:1 in 1997 to 9.3:1 in 2007 (Census and Statistics Department 2008) but the student-teacher ratios in three of the kindergartens were higher than this. This may be because administrative and non-teaching staff such as principals, head teachers, and curriculum coordinators had been counted as teachers in the government statistics. In this study, the average student-teacher ratio was $15: 1$.

\section{Teacher-Child Interactions}

\section{Frequency of Interactions}

Our findings indicated that approximately 536.85 incidents of teacher-child interactions were enacted in a Chinese kindergarten classroom of the 4-year-olds in Hong Kong per typical school day, if the class size is 30 , gender ratio of the children is $1: 1$, and there is an assistant teacher to help the class teacher regularly. The estimate is based on the data which were coded quantitatively and indicate that there were 8.16 teacher-boy interactions per head per hour and 3.78 teacher-girl interactions per head per hour. It is reasonable to conclude that the quantity of teacher-child interactions was abundant in the Chinese kindergartens studied.

Consistent with the findings of a meta-analysis of teacher-student interactions in the U.S. (Jones and Dinda 2004), we found that the female Chinese kindergarten teachers in the study had more interactions with boys than with girls. Teachers inadvertently granted boys more attention than girls and interacted with boys twice as much as they interacted with girls. However, it is worth mentioning that the quality of the children's educational experiences should be a more important concern if education for all is recognized as the educational goal and the right of our children.

\section{Quality of Teacher-Child Interactions}

The majority of teacher-child interactions were positive and kindergartens in Hong Kong appear to be a pleasant coeducational setting for children. Although teachers interacted with boys more than they did with girls, more indepth analyses indicated that the teachers were fond of girls. About $73 \%$ of teacher-girl interactions were positive and only $12 \%$ were negative in nature. On the other hand, boys experienced more neutral and negative interactions with teachers than girls. Observations suggested that the 
teachers blamed boys more than girls for any off-task behaviors.

Hamre and Pianta (2001) found that the teacher-child relational negativity marked by high conflict and overdependence in kindergartens mediated academic and behavioral outcomes through the 8th grade in the U.S. particularly for boys and children with high levels of behavior problems. It is possible that teachers' expectations of higher academic engagement but weaker self-regulation for the 4-year-old Chinese boys in this study may undermine their future self-efficacy in academic achievement and self-determination, which might in turn lead to lower self-esteem as they mature.

\section{Children's Behavior and Differential Attention}

Observations also suggested that the 4-year-old girls managed to complete tasks successfully and in socially desirable ways most of the time. Hence, we believe that the relatively good behavior and performance of the majority of girls in the present study may have led to them receiving less teacher attention. In the same vein, the immature and mischievous behaviors of some boys might have earned them more attention.

\section{Perpetuation of Gender Stereotypes}

In keeping with results from studies on kindergarten teachers and children in the U.S. (Chick et al. 2002; Martin 1998), content analysis of the observations conducted in the present study indicated that kindergarten teachers were the major agents who perpetuated gender stereotypes in the kindergartens. These behaviors have their roots in traditional Chinese beliefs and practices. For over 2,000 years, Chinese boys have been socialized to be heads of families and to be leaders, but Chinese girls were socialized to be obedient wives and trained to be capable homemakers (Chen 1997; Sturgeon 2008, 2009; Theobald 2000).

Male privilege such as the "Boys First" rule was observed consistently and frequently but the 4-year-old girls did not protest about the unfairness. The Chinese teachers consistently contributed to the gender socialization of their children by practicing gendered kindergarten routines and differential attention. On a daily basis, girls experienced gender inequity while boys learnt about male privilege. Young children learned about and experienced traditional and male-centered Chinese culture in the miniature society of kindergartens. Although it appears that by the age of four, girls have already learned to accept male privilege, it may not be appropriate to infer that this is acceptable and problem free just because the girls rarely grumbled and did not complain.
Male privilege was particularly evident in the two kindergartens with lower teacher-student ratios and older interior designs. The less favorable ratios and the long distance between the boys' toilet and the girls' toilet notably sharpened the conflict of interest between the two gender groups of children during toilet time. The large class size may have led teachers to give more attention to boys at the expense of girls. Just like parents in rural China who gave priority to their sons over their daughters (Cai and William 2003), these Chinese teachers did not provide their girls with as much care and attention as they bestowed upon boys.

Interestingly the female first author and the man who considered the coding of some of the anecdotes differed most markedly in their interpretation of who benefitted from differential treatment. The first author felt that teacher gave boys more attention and care both in (e.g., during whole class teaching) and out of the classroom (e.g., lining up to go to the toilet) and that boys benefitted from this differential treatment. The man agreed that there was differential treatment but felt that girls were the beneficiaries of differential treatment to boys and girls. Having a larger sample of men and women from different backgrounds interpret data will allow a better understanding of if and how gender influences interpretations of observed events.

In summary, kindergarten teachers in Hong Kong gave 4-year-old Chinese boys more attention than girls and they were also less tolerant of boys' off-task behavior than they were of girls. On the other hand, the 4-year-old girls experienced male-centeredness but higher teacher-child relational positivity and teachers may have negative stereotypes about the nature of boys which leads them to give more attention to boys. The reciprocal effect of social cognitions and observational learning might have long term detrimental influences upon the self-image of the Chinese boys and the self-esteem of the Chinese girls (Bussey and Bandura 1999).

\section{Conclusions}

Findings from studies conducted in the U.S. have suggested that teachers inadvertently perpetuate gender stereotypes (Chick et al. 2002; Sadker and Sadker 1994; Walkerdine 1998). We found that female Chinese kindergarten teachers perpetuated traditional Chinese gender values, beliefs, and stereotypes in their interactions with children on a daily basis. Their common and typical contributions to gender socialization of Chinese children included gendering the kindergarten teaching profession, being role models for girls, being the authority in the teacher-directed kindergarten classrooms, using gender labels extensively and functionally with the gendered kindergarten routines, practicing differential attention, and granting male privilege. 
Findings from this study also highlighted the subtle and implicit mode of the participating teachers' contributions to gender socialization featured a male-centered hidden curriculum. The female Chinese kindergarten teachers subtly but actively acted as the constituent part of the hidden curriculum of gender. They endorsed and reinforced the long-held malecentered values of traditional China repeatedly by exercising their authority in the Chinese kindergartens of Hong Kong. The take-it-for granted attitude among the 4-year-old boys and girls toward the manifestation of male privilege has been developed as an observable learning outcome of the hidden curriculum of gender.

Bronfenbrenner's (1989) ecological systems theory perceives socialization as an interwoven and reciprocal process. In the study, gender socialization of Chinese 4-year-olds was examined in the physical, socio-cultural, relational, and institutional context of the participating coeducational Chinese kindergartens as a whole. Notwithstanding that tangible conditions such as the teaching materials for boys and girls appeared equivalent, warnings and opinions of nongovernment associations and researchers in western societies (AAUW 1992; Jackson and Lahaderne 1976; Koch 2003; Sadker and Sadker 1994; and Sheldon 2004) were taken into account when the issue of fairness was considered. It was felt that the 4-year-old Chinese girls were not provided with gender equity in the quality of education. On the other hand, our findings are consistent with some previous studies on the issues in boys' education in western societies (Ashley and Lee 2003; Connolly 2004; Epstein et al. 1998) and suggested that boys were not necessarily the beneficiary when girls suffered from gender inequity.

Based on the findings in the present study, our responses to the two research questions are as follows: First, the participating Chinese teachers contributed to gender socialization in subtle ways similar to those of the teachers in western societies while the Chinese 4-year-olds experienced gendered routines and differential attention like the children in co-educational settings in western societies. Second, it was confirmed that male privilege manifested in the participating Chinese kindergartens in Hong Kong. However, existing practice of granting boys privilege could be a kind of overprotection. Such kind of overprotection may ultimately disempower Chinese boys and not necessarily benefit them.

In spite of the small sample of teachers and kindergartens, the study cautions re-examinations of the Chinese kindergarten teachers' gender socialization goals and strategies. Our study has asserted that Chinese teachers should be conscious about status as role models and be equally concerned about the welfare of boys and girls. Chinese kindergarten teachers should be aware that gender differentiation would not be a rewarding socialization experience for both the Chinese boys and girls.
Importantly, it was noted the granting of male privilege may not benefit the boys, but obviously perpetuate undesirable gender stereotypes and inequity. Chinese kindergarten teachers may avoid segregating boys from girls in kindergartens for the purpose of convenience, desist from micromanaging the classroom behaviors of boys, be aware of the gender values and stereotypes they uphold, and mind the importance of teacher-child relational positivity to child development.

Albeit its gender-bias and ethnic Chinese sample, our small-scale study wished to provide some insights for further cross-cultural psychological studies on the ecology of gender development. We had only intensively investigated the female Chinese teachers' contributions to gender socialization of the 4-year-olds in four Chinese kindergartens in Hong Kong SAR of China over 10 months. The findings from this study need to be replicated in other Chinese kindergartens in Hong Kong by observers who are blind to the hypotheses.

In view of the ecological systems perspective of child development, further studies may attempt to feature the comparison between the contributions of male and female kindergarten teachers to gender socialization of Chinese children across different Chinese societies. In view of the social-cognitive theoretical perspective, future studies may also investigate the relative impact of self-regulations in children and various gender-typing forces across situational circumstances and activity domains over time.

Acknowledgement This article is based on research conducted by the first author, in partial fulfillment of the requirements of a $\mathrm{PhD}$ degree (2006), under the supervision of the second author. Portions of this paper were presented at the 18th Biennial Meeting of the International Society for the Study of Behavioral Development (ISSBD), Ghent, Belgium, 2004, and 64th Convention of the International Council of Psychologists (ICP), Kos, Greece, 2006.

Open Access This article is distributed under the terms of the Creative Commons Attribution Noncommercial License which permits any noncommercial use, distribution, and reproduction in any medium, provided the original author(s) and source are credited.

\section{References}

AAUW Report. (1992). How schools shortchange girls: A study of major findings on girls and education. Washington, DC: American Association of University Women Educational Foundation.

Alloway, N. (1995). Foundation stones: The construction of gender in early childhood. Australia: Curriculum Corporation.

Ashley, M., \& Lee, J. (2003). Women teaching boys: Caring and working in the primary school. Stroke on Trent: Trentham Books.

Best, R. (1983). We've all got scars: What boys and girls learn in elementary school. Bloomington: Indiana University Press.

Bem, S. L. (1981). Gender schema theory: A cognitive account of sextyping. Psychological Review, 88, 354-364.

Bigler, R. S. (1995). The role of classification skill in moderating environmental influences on children's gender stereotyping: A 
study of the functional use of gender in the classroom. Child Development, 66, 1072-1087.

Blaise, M. (2005). A feminist poststructuralist study of children "doing" gender in an urban kindergarten classroom. Early Childhood Research Quarterly, 20, 85-108.

Blaise, M., \& Andrew, Y. (2005). How "bad" can it be?: Troubling gender, sexuality, and early childhood teaching. In N. Yelland (Ed.), Critical issues in early childhood (pp. 49-57). NY: Open University Press.

Bronfenbrenner, U. (1989). Ecological systems theory. In R. Vasta (Ed.), Annals of child development. Six theories of child development: Revised formulations and current Issues (pp. 187-249). London: JAI.

Bussey, K., \& Bandura, A. (1999). Social cognitive theory of gender development and differentiation. Psychological Review, 106, 676-713.

Cai, Y., \& William, L. (2003). China's missing girls: Numerical estimates and effects on population growth. The China Review, 3, 13-29.

Census and Statistics Department. (2008). Hong Kong annual digest of statistics: 2008 edition. Hong Kong: Hong Kong Government.

Chen, J. R. (1997). An de zhang zhe yan [The old adages]. Shandong, China: Qilu. (Original work published 1599).

Chick, K., Heilman-Houser, R., \& Hunter, M. (2002). The impact of child care on gender role development and gender stereotypes. Early Childhood Education Journal, 29, 149-154.

Connolly, P. (2004). Boys and schooling in the early years. London: RoutledgeFalmer.

Creswell, W. J. (2005). Educational research: Planning, conducting, and evaluating quantitative and qualitative research ( $2 \mathrm{nd} \mathrm{ed}$.$) .$ Upper Saddle River: Pearson Education, Inc.

Curriculum Development Council (2006). Guide to pre-primary curriculum. Hong Kong: Hong Kong Government. Retrieved from http://www.emb.gov.hk/FileManager/EN/Content_2405/ pre-primaryguide-net_en.pdf.

Diekman, A., \& Murnen, $\overline{\text { S }}$. (2004). Learning to be little women and little men: The inequitable gender equality of nonsexist children's literature. Sex Roles, 50, 373-385.

Duffy, J., Warren, K., \& Walsh, M. (2001). Classroom interactions: Gender of teacher, gender of student, and classroom subject. Sex Roles, 45, 579-593.

Eckert, P., \& McConnell-Ginet, S. (2003). Language and gender. United Kingdom: Cambridge University Press.

Epstein, D., Elwood, J., Hey, V., \& Maw, J. (Eds.). (1998). Failing boys? Issues in gender and achievement. Great Britain: Open University.

Equal Opportunities Commission (2001). Hong Kong court cases. Retrieved from http://www.eoc.org.hk/EOC/GraphicsFolder/ showhkcc.aspx?id=2746.

Fagot, I., Hagan, R., Leinbach, D., \& Kronsberg, S. (1985). Different reaction to assertive and communicative acts of toddler boys and girls. Child Development, 56, 1499-1505.

Family Planning Association. (1984). Family planning knowledge, attitude and practice in Hong Kong. Hong Kong: Family Planning Association.

Family Planning Association. (1989). Report on the Survey of Family planning knowledge, attitude and practice in Hong Kong. Hong Kong: Family Planning Association.

Family Planning Association (1997). KAP Survey Report 1997. Retrieved from http://www.famplan.org.hk/fpahk/en/template1. asp?style=template 1 .asp\&content $=$ info/publications/kap97.asp.

Fong, V. (2002). China's one child policy and the empowerment of urban daughters. American Anthropologist, 104, 1098-1109.

Fromberg, D. (2005). The power of play: Gender issues in early childhood education. In J. Koch \& B. Irby (Eds.), Gender and schooling in the early years (pp. 1-27). Greenwich: IAP.

Hamilton, M. C., Anderson, D., Broaddus, M., \& Young, K. (2006). Gender stereotyping and under-representation of female charac- ters in 200 popular children's picture books: A twenty-first century update. Sex Roles, 55, 757-765.

Hamre, B., \& Pianta, R. (2001). Early teacher-child relationships and the trajectory of children's school outcomes through eighth grade. Child Development, 72, 625-638.

Hsieh, H.-C. (1995). Gender differentiation of educational experiences in a changing Taiwan. In G. Postiglione \& W.-O. Lee (Eds.), Social change and educational development: Mainland China, Taiwan and Hong Kong (pp. 207-230). Hong Kong: Hong Kong University Press.

Jackson, P., \& Lahaderne, H. (1976). Inequalities of teacher-pupil contacts. Psychology in the Schools, 4, 204-208.

Jones, S. M., \& Dinda, K. (2004). A meta-analytic perspective on sex equity in the classroom. Review of Educational Research, 74, $443-471$.

Koch, J. (2003). Gender issues in the classroom. In W. M. Reynolds \& G. E. Miller (Eds.), Handbook of psychology (Educational Psychology, Vol. 7, pp. 259-281). Hoboken: Wiley.

Laflamme, D., Pomerleau, A., \& Malcuit, G. (2002). A comparison of fathers' and mothers' Involvement in childcare and stimulation behaviors during free-play with their infants at 9 and 15 months. Sex Roles, 47, 507-518.

LeVine, R. A. (1998). Child psychology and anthropology: An environmental view. In C. Panter-Brick (Ed.), Biosocial perspectives on children (pp. 102-130). United Kingdom: Cambridge University Press.

Maccoby, E. E. (1998). The two sexes: Growing up apart, coming together. Cambridge: Belknap/Harvard University Press.

Maccoby, E. E. (2000). Perspectives on gender development. International Journal of Behavioral Development, 24, 398406.

Martin, K. A. (1998). Becoming a gendered body: Practices of preschools. American Sociological Review, 63, 494-511.

Morgan, C. (2001). The Effects of Negative Managerial Feedback on Student Motivation: Implications for Gender Differences in Teacher-Student Relations. Sex Roles, 44, 513-515.

Oskamp, S., \& Kaufman, K. (1996). Gender role portrayals in preschool picture books. Journal of Social Behavior and Personality, 11, 27-40.

Ruble, D., \& Martin, C. (1998). Gender development. In W. Damon (Series Ed.) \& N. Eisenberg (Ed.) Handbook of Child Psychology: Vol. 3. Social, emotional, and personality development (5th ed., pp. 933-1016). New York: Wiley.

Sadker, M., \& Sadker, D. M. (1994). Failing at fairness: How America's schools cheat girls. New York: C. Scribner's Sons.

Salaff, J. W. (1995). Working daughters of Hong Kong: Filial piety or power in the family? New York: Columbia University Press.

She, H.-C. (2000). The interplay of a biology teacher's beliefs. Teaching practices and gender-based student-teacher classroom interaction. Educational Research, 42(1), 100-111.

Sheldon, J. P. (2004). Gender stereotypes in educational software for young children. Sex Roles, 51, 433-444.

Sturgeon, D. (Trans.) (2008). The Chinese text project. Retrieved from $\mathrm{http} / / /$ chinese.dsturgeon.net/text.pl?node $=9895 \& \mathrm{if}=\mathrm{en} \& \mathrm{en}=\mathrm{on}$.

Sturgeon, D. (Trans.) (2009). The Chinese text project. Retrieved from $\mathrm{http}: / /$ chinese.dsturgeon.net/text.pl?node $=1670 \& \mathrm{if}=\mathrm{en} \& \mathrm{en}=\mathrm{on}$.

Theobald, U. (Trans.) (2000). Chinese Literature Daxue "The Great Learning". Retrieved from http://www.chinaknowledge.de/Liter ature/Classics/daxue.html.

Thorne, B. (1993). Gender play: Girls and boys in school. Buckingham: Open University Press.

Walkerdine, V. (1998). Counting girls out: Girls and mathematics. London: The Falmer.

Williams, J. E., \& Best, D. L. (1982). Measuring sex stereotypes: A thirty-nation study. Beverly Hills: Sage. 